\title{
The numerical modeling and the infrared thermography principle applied to the analysis of corrosion defects in oil Conduits
}

\author{
by Naouar LAAIDI1, Sougrati BELATTAR2*
}

\author{
1Laboratory of Electronics, Instrumentation and Signal Processing \\ Faculty of Sciences, B.P 20. 24000 El Jadida, Morocco \\ 2Department of physics, Faculty of Sciences Semlalia, B.P. 239/40000/ Marrakech, Morocco \\ *belattars@hotmail.com
}

\begin{abstract}
Currently the corrosion phenomenon becames a serious concern to several industries of metals and particularly of steel like nuclear, chemical and petrol industries. Such defects can occur severe economic and social damage, that's why it's so important to detect them as soon as possible to avoid those lost. The purpose of the study is to show by calculating of surface temperature the effect of corrosion defect which can exist in these conduits. To undertake the study we modelled conduit (tube) by a steel cylinder and the defect by a circular layer of rust. Dimensions of the cylinder and those of the layer of rust are taken as parameters. To see the effect of each geometrical parameter on the thermal state of the considered structure we studied the thermal state of the structure by taking this parameter like variable and all the others as constant.

In fact, when a material is thermically requested (artificial excitation in the case of Laboratory measurements or natural excitation in the case of in-situ measurements), the heat diffuse in uniform way in material. The presence of a defect within the material (e.g. a crack or a rusted layer) acts like a heat insulator and idle this diffusion. It follows from there the appearance of a hotter region on the surface compared to the close one without anomaly. The study is undertaken on a cylindrical structure, as on the figure below, of geometrical parameters: external diameter $d=254 \mathrm{~mm}$. The cylinder thickness ep $=19 \mathrm{~mm}$, the length of tube $\mathrm{I}=1 \mathrm{~m}$. In order to detect the rust thermal effect on the thermal state of the steel pipe, many situations are considered. The study concerns the effect of rust thickness, rust depth and finally the number of rust layers in pipe on the surface temperature at the structure.
\end{abstract}

Keywords: corrosion, conduits, steel, infra-red ther thickness mography, finite elements.

\section{Introduction}

The corrosion defect is one of serious concern to several industries like nuclear, chemical and petrol industries. Such defects can occur severe economic and social damage, that's why it's so important to detect them as soon as possible to avoid those lost $[1,2]$.

The purpose of the study is to show by calculating of surface temperature the effect of corrosion defect which can exist in these conduits.

To undertake the study we modelled conduit (tube) by a steel cylinder and the defect by a circular layer of rust. Dimensions of the cylinder and those of the layer of rust are taken as parameters. To see the effect of each geometrical parameter on the thermal state of the considered structure we studied the thermal state of the structure by taking this parameter like variable and all the others as constant.

\section{Principle of the Method}

When a material is thermically requested (artificial excitation in the case of Laboratory measurements or in-situ measurements), the heat diffuse in uniform way in material. The presence of a defect within the material (e.g. a crack or a rusted layer) acts like a heat insulator and idle this diffusion. It follows from there the appearance of a hotter region on the surface compared to the close one without anomaly [3].

\section{Structure of Model}

The study is undertaken on a cylindrical structure of geometrical parameters: external diameter $\mathrm{d}=254 \mathrm{~mm}$. The cylinder thickness $\mathrm{eP}=19 \mathrm{~mm}$, the length of tube $\mathrm{I}=1 \mathrm{~m}$. 


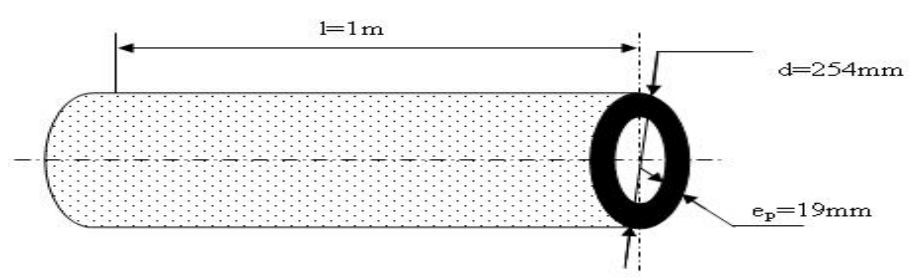

Fig.1. studied structure

\section{Mathematical Model}

To solve the following thermal equation:

$$
a \nabla^{2} T=\frac{d T}{d t}
$$

were the report $a=\frac{\lambda}{\rho c}$ is called thermal diffusivity.

We call upon the numerical method of the finite elements [4, 5]. The analytical resolution is indeed impossible being given the geometry of the problem. The method consists in using an approximation by finite elements of the unknown functions $T$ to discretize the variational form of the equation (1) and to transform it into system of algebraic equations of the form:

[A] $T=F$.

With:

A square matrix of dimension [ $\mathrm{Nh}, \mathrm{Nh}$ ].

$\mathrm{F}$ a vector of $\mathrm{Nh}$ components.

$\mathrm{T}$ the vector of the temperatures to be calculated

We start by building the variation form of the equation (1). We carry out a spatial discretization which consists in calculating the elementary integrals by using the finite element and a temporal discretization.

There are many specialized software which make it possible to implement the method of resolution of problems by finite elements in a more or less simple and convivial way. They take care in particular of the grid of the studied object, the automatic numbering of the elements and the nodes, the calculation of a solution then of the chart of the results.

In this study, we used commercial software "Comsol" based on the finite element method and which makes it possible to calculate the evolution of temperature at any moment and in any point of material. The material is considered isotropic. The calculation of the thermal answer is made in the case of a portion of oil pipe, subjected to a level of flow on the outer face, continuous and is extended from $Q=50 \mathrm{~W} / \mathrm{m} 2$ density. the Inner surface of the pipe were subjected to convectional heat transfer with heat transfer coefficient, $h=10 \mathrm{~W} / \mathrm{m}^{2} . \mathrm{K}$. The initial temperature is of $\mathrm{T} 0=25^{\circ} \mathrm{C}$.

\section{Result of Simulation}

\subsection{Considered model}

In order to detect the rust thermal effect on the thermal state of the steel pipe, many situations are considered. The study concerns the effect of rust thickness, rust depth and finally the number of rust layers in pipe on the surface temperature at the structure.

Generally, from a thermal point of view the rust element is compared to water, since both have very close thermal characteristics [6]. When the rust attacks a cylindrical structure, the steel section decreases with the increase of corrosion layer [7], which involves a no homogeneous reduction of steel section accompanied by its embrittlement and a modification of the interface physical properties (increase then reduction in adherence) [8].

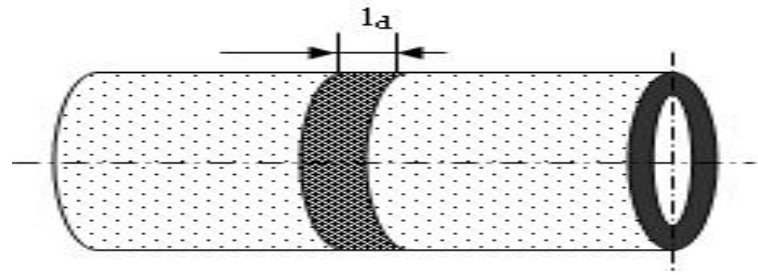

Fig.2.a. pipe with defect

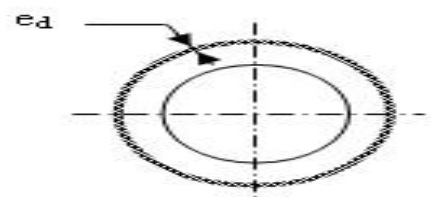

Fig.2.b. cross section of steel conduit

Fig.2. considered model 


\subsection{Effect of the rust width}

In order to illustrate the effect of the width of the rusted layer on control, one considered 3 three layers of rust in the shape of circular layer of a constant thickness $(7 \mathrm{~mm})$ and with variable widths: $0.5 \mathrm{~cm}, 1 \mathrm{~cm}$ and $5 \mathrm{~cm}$. The thermographical images (figures 4,5, 6 and 7)and the surface temperature curves fig. 8 obtained show that the more the width of rust increases, the more the surface temperature of the entry face increases and consequently the detectability of the defect becomes easier.

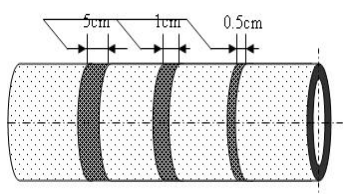

Fig.3.structure of model

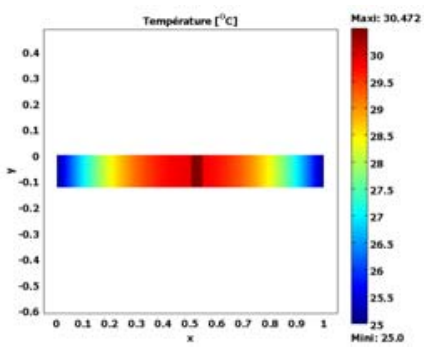

Fig.6. Thermographical image of the entry face $(\mathrm{ld}=5 \mathrm{~cm})$

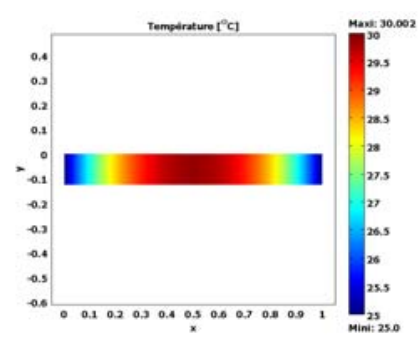

Fig.4. Thermographical image of the entry face $(l d=0.5 \mathrm{~cm})$

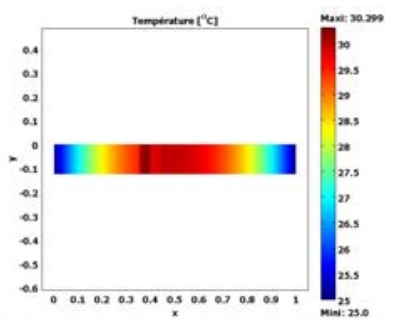

Fig.7. Thermographical image of the entry face for the three cases together

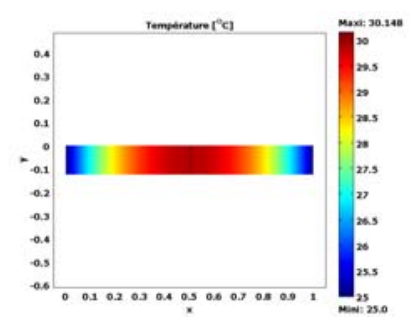

Fig.5. Thermographical image of the entry face $(l d=1 \mathrm{~cm})$

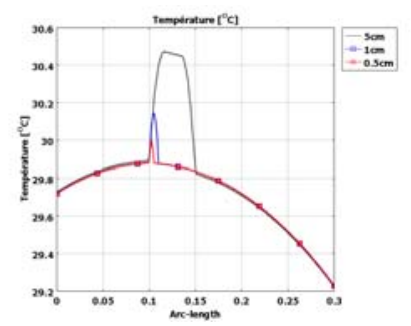

Fig.8. Spatial evolution of the temperature on the entry face

\subsection{The effect of rust thickness}

The same pipe used before is considered and this time the thickness takes the following values: $4 \mathrm{~mm}$, $6 \mathrm{~mm}$ and $9 \mathrm{~mm}$. The width of the layer is constant and equal to $5 \mathrm{~cm}$. The thermographical images of the three cases (figures 10,11, 12 and 13)and the surface temperature curves fig.14 obtained show that the more the rust thickness increases, the more the surface temperature of the entry face also increases and consequently the detectability of these defects becomes easier.

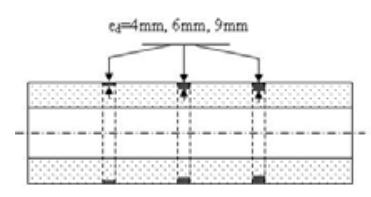

Fig.9. structure of model

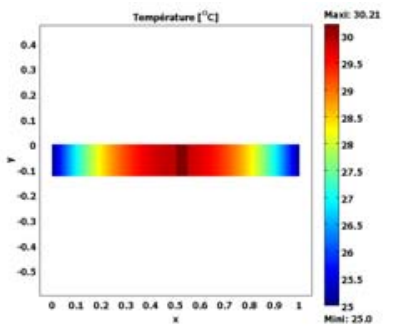

Fig.10. Thermographical image of the entry face $(\mathrm{ed}=4 \mathrm{~cm})$

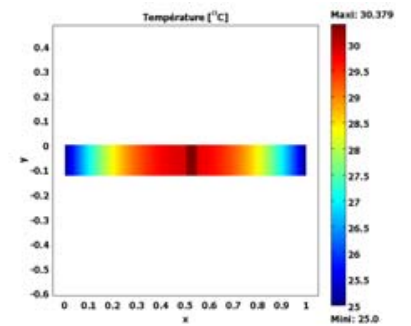

Fig.11. Thermographical image of the entry face $(\mathrm{ed}=6 \mathrm{~cm})$ 


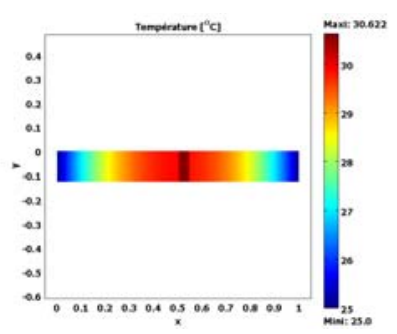

Fig.12. Thermographical image of the entry face $(\mathrm{ed}=9 \mathrm{~cm})$

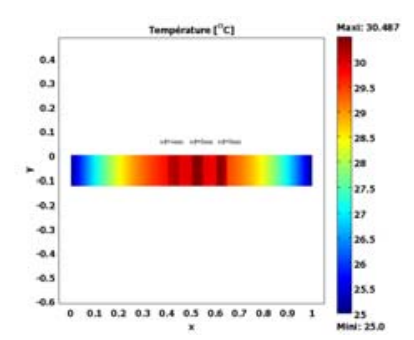

Fig.13. Thermographical image of the entry face for the tree cases together

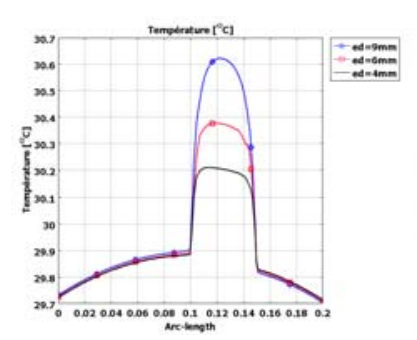

Fig.14. change of the temperature on the entry face

\subsection{Effect of the variable thickness of pipe}

In this case of study, the variable parameter is the thickness of the pipe. This time one take as values $\mathrm{ep}=19 \mathrm{~mm}, 14 \mathrm{~mm}$ and $12 \mathrm{~mm}$, and one will study the detectability of the layer of rust having a constant thickness equal to $6 \mathrm{~mm}$ and constant width equal to $1 \mathrm{~cm}$.

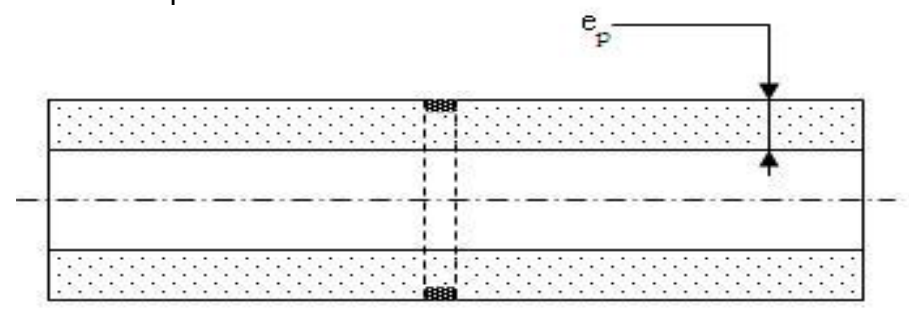

Fig.15. structure of model

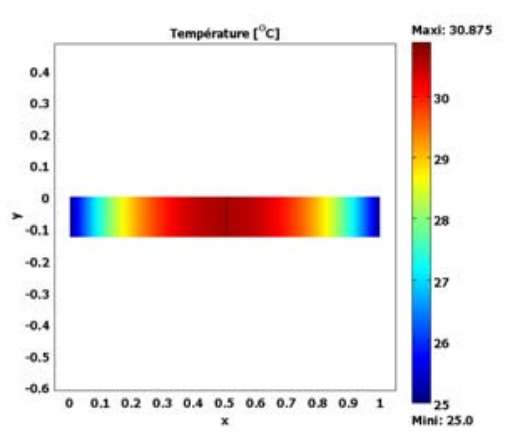

Fig.16. Thermographical image of the entry face $\left(e_{p}=12\right.$ $\mathrm{cm})$

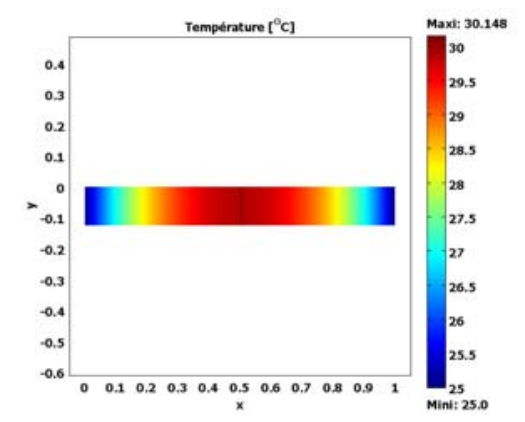

Fig.18. Thermographical image of the entry face $\left(e_{p}=19\right.$ $\mathrm{cm}$ )

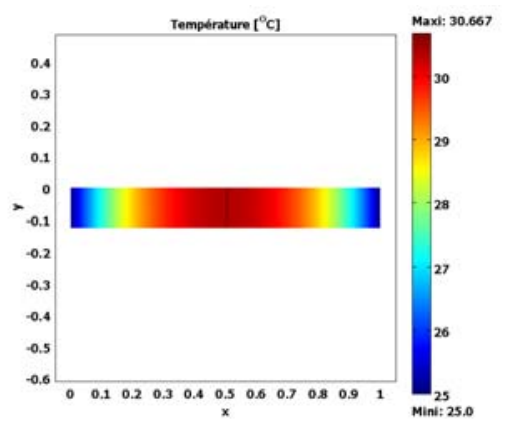

Fig.17. Thermographical image of the entry face $\left(e_{p}=14 \mathrm{~cm}\right)$

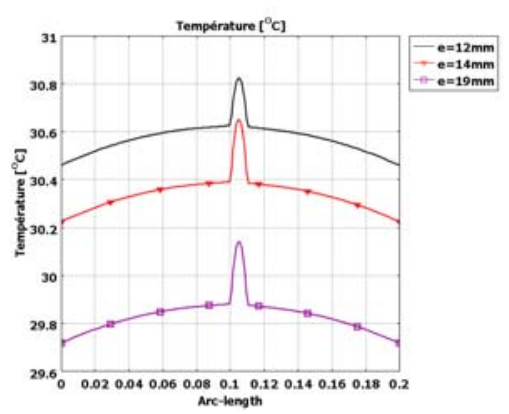

Fig.19. change of the temperature on the entry face 
Equally from these curves it comes out that when the thickness of the pipe is low, the delectability of the presence of rust in the controlled structure is relatively easy according to the thermographical images (figures: 16, 17 and 18) and also on the level of the spatial evolutions of the surface temperatures of pipe fig.19. The detection of the defect of rust will be more difficult for a larger thickness of control.

\section{Conculsion}

In this paper, we presented the effect of several parameters of the rust layer on its delectability in steel conduits, namely the effect of its width and its thickness. The effect of the pipe thickness was also considered. In general, one can draw the following conclusions:

- The detectability of corrosion is easier for a larger rust thickness .

- The detectability is easier for a larger width.

- More the thickness of pipe is low more the easier of detectability of defect is.

\section{REFERENCES}

[1] A. Vageswar et al.Periscope: infrared thermography for local wall thinning in tubes. NDT\&E International 42 (2009) 275-282

[2] J.-H. Lee, S.-J. Lee: Application of laser-generated guided wave for evaluation of corrosion in Carbon steel pipe. NDT\&E International 42 (2009) 222-227.

[3] J. RHAZI, S. NAAR. : Aptitude de la thermography infrarouge à détecter les fissures et nids d'abeille dans le béton.

[4] A. Elballouti, S. Belattar. : Numerical method applied to the non-destructive characterization of the cracks in the roadways. Physical \& Chemical News 35 (May 2007) 43-47.

[5] A. Obbadi, S. Belattar : Vth international workshop, Advances in Signal processing for non destructive evaluation of materials, 6(2006) 203-208 (Canada, Quebec).

[6] Molina F.J., Alonso C., Andrade C. (1993). : Cover cracking as a function of rebar corrosion. Part 2 Numerical model. Materials and Structures, vol. 26, p. 532-548.

[7] Mickael Dekoster, Olivier Blanpain, François Buyle-Bodin, Olivier Maurel : Etude de l'évolution des coefficients de sécurité des ouvrages en béton armé dégradé selon différents scénarios de corrosion.

[8] Quang Thanh Nguyen, Sabine Caré, Yves Berthaud, A. Millard : Fissuration du béton soumis à la corrosion. L'objet. Volume 8 - n॰2/2005. 